\title{
DYNAMIC BEHAVIOR OF UPPER HYDRAULIC DRIVE CONTROL ROD
}

\author{
Xiaotian Li \\ Institute of nuclear and new energy \\ technology, Beijing 100084, China \\ E-mail: lixiaotian@tsinghua.edu.cn
}

\author{
Zhongjie Zhang \\ Institute of nuclear and new energy \\ technology, Beijing 100084, China
}

\author{
Shuyan He \\ Institute of nuclear and new energy technology, Beijing 100084, China
}

\begin{abstract}
200MW nuclear heating reactor (NHR) is developed based on 5MW testing heating reactor (THR-5). If 200MW NHR is constructed as commercial demonstration reactor, it will be used as heat source for desalination or urban heat supply. In order to improve its economics INET has been optimized its structure design. The upper hydraulic drive control rod just is the optimization result. the control rod drive is located at the upper part of reactor core, the fuel rod in each corner of the bundle will not be removed as THR-5. In order to investigate the dynamic behavior of the upper control rod driving system, the method of characteristics based on solving the equations of continuity and momentum is used. The mathematical model includes all component modules (pump, valve, impulse cylinder, drive cylinder, etc.). The typical actions of control rod, withdraw, insertion and scram with relation to the parameters of driving system are studied sufficiently. The variation of physical parameters will lead to vary of dynamic behavior of control rod certainly. The temperature characteristic of hydraulic drive control rod is important on its reliable operating. This paper will this question and obtain the reasonable design parameters.
\end{abstract}

Keywords: Hydraulic drive, Control rod, Method of characteristics, Dynamics

\section{INTRODUCTION}

200MW Nuclear Heat Reactor(NHR-200) is developed based on 5MW Testing Heating Reactor (THR-5) located at Tsinghua University. Its main characteristic is inherent safety, low invest and short construction period. If NHR-200(2003) is constructed as commercial demonstration reactor, it will be used as heat source for desalination or urban heat supply.

In order to improve the features of NHR, some research work on design optimization has been done. This paper is one of them. The reactor system of NHR-200 is highly compact, hydraulic driven control rod which could be arranged in reactor vessel is used. In the former design(1987,1999), as a result of the driving cylinder of hydraulic driven control rod being located in the reactor core, three fuel rods in each corner of fuel assembly were removed, the thickness of the driving cylinder only was $2 \mathrm{~mm}$ in order to decrease neutron absorption. It will lead to manufacturing difficultly and deterioration of driving performance. In this paper a new hydraulic driven control rod called as upper hydraulic drive control rod, which just is the result of reactor structure optimization is designed.

\section{PRINCIPLE OF OPERATION}

Figure. 1 is schematic diagram of the flow in the upper hydraulic driven control rod. Water is extracted from RPV and pumped into inlet of cylinder passing through hold throttle. One of water flow out from the upper labyrinth, the other from the lower gap of cylinder. At a certain flow, the piston will hold a stationary position while the pressure on the piston is balance with its weight. This flow is called as hold flow. Hold flow is adjusted using 
the hold throttle. Maximum hold flow is that at which the control rod will be withdrawn a step if adding a little flow; minimum hold flow is that at which the control rod will be moved into core a step if reducing a little flow. The operating hold flow is always between the maximum and minimum hold flow.

Normally withdrawal valve is opened and insertion valve is closed. To withdraw the control rod by one step, withdrawal electromagnetic valve is firstly closed over predetermined short period time to inject water into the impulse cylinder, then opened to generate additional flow by pushing out of water from impulse cylinder. To move the control rod into the core by one notch, insertion valve is opened temporarily to bypass a part of the hold flow.

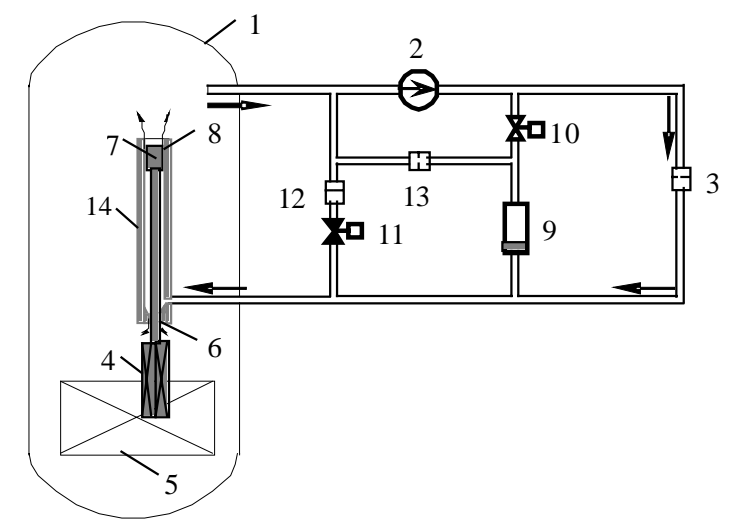

Fig. 1 Flow scheme of upper hydraulic drive control rod system

\author{
1-RPV 2-Pump 3-Hold throttle 4-Control blade 5-Reactor core \\ 6-Notch 7 -Piston 8-Labyrinth 9 -Impulse cylinder \\ 10 -Withdrawal valve 11 -Insertion valve 12 -Insertion throttle \\ 13 - Bypass throttle 14 -Cylinder
}

\title{
3. DESIGN OF THE UPPER HYDRAULIC DRIVEN CONTROL ROD
}

Figure. 2 shows the position of upper hydraulic driven control rod in the reactor vessel. The cylinder of new upper hydraulic driven control rod is arranged above the reactor core and control rod is moved with the floating piston. Therefore the number of fuel rod in the active zone is increased, the ratio of water to uranium and neutron absorption are decreased. The diameter and thickness of the cylinder could properly be enlarged within the space above the reactor core. It is benefit to lower power of driving pump, simple fabrication and inspection.

\subsection{Structure description}

As shown in Fig.3, the upper hydraulic driven control rod consists of the cylinder fixed to the control rod support frame and a movable piston to which the connecting bar is affixed. The lower part of the cylinder is perforated and the connecting bar passes though the hole. The control blades are fixed to the lower third of the connecting bar which length is about three times control blades. The connecting bar has notches over its upper two-part length. At the inner of perforated cylinder there are a number of the notches. The lateral piston is labyrinthic structure. 

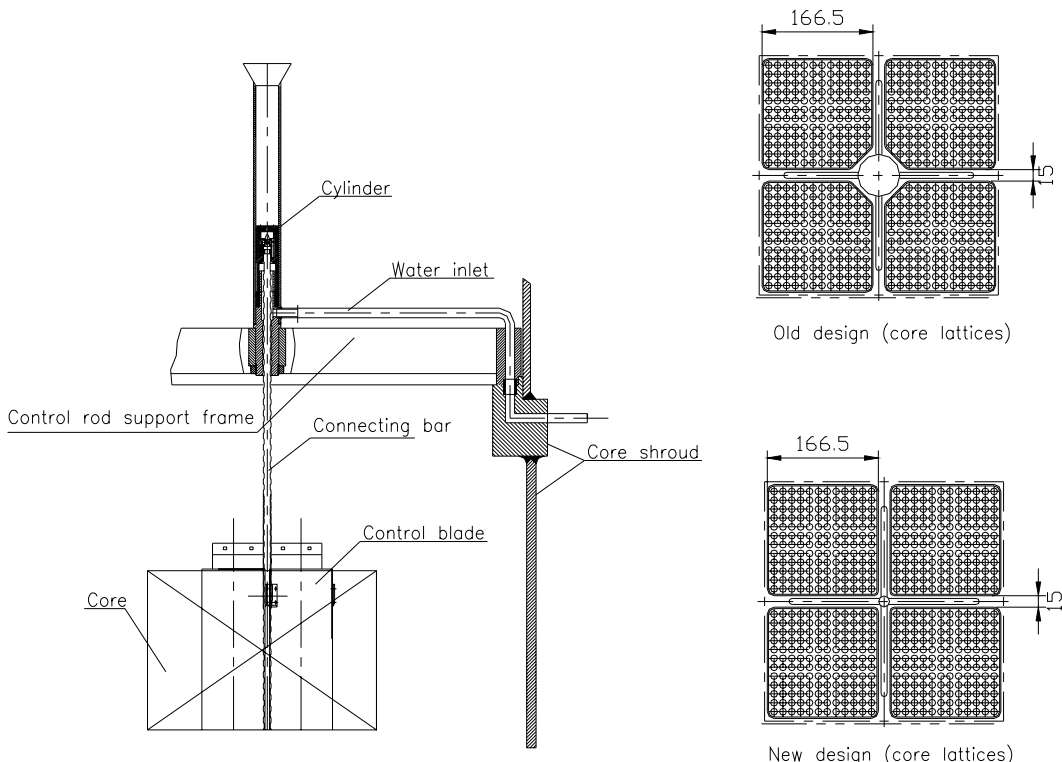

Fig.2 Schematic structure of upper hydraulic driven control rod

Pressurized water enters the drive cylinder through water inlet and exerts a force on the piston equivalent to the weight of the piston and the control blades. The flow pass through the lower gaps which is formed by the notches in the annulus between the connecting bar and the cylinder, and upper gap between the piston and the cylinder. As the flow increases, the piston moves up slightly. This enlarges the gaps and accommodates the increased outlet flow. In turn, equilibrium is restored between the flow forces and the weight of the piston. The control rod remains in a definite position over a wide range of flow rates between maximum and minimum flow rate. Increasing the flow rate beyond the point where it is no longer possible to increase the gap causes the control rod to move upward. The reduction of the flow rate results in the control rod downward motion.

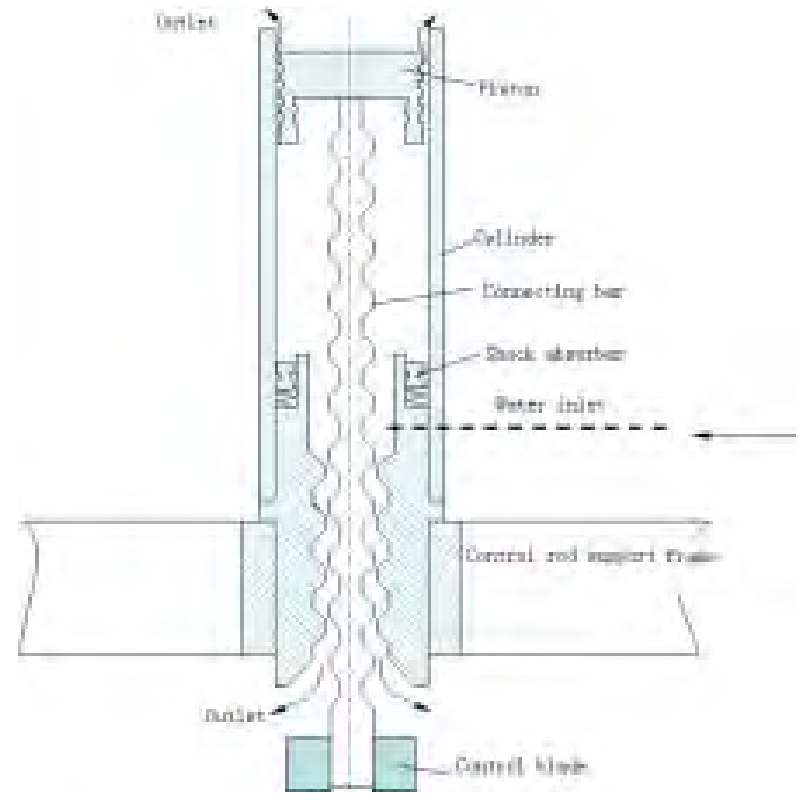

Fig.3 Schematic view of upper hydraulic driven cylinder

The shock absorber is located at the bottom of the cylinder to absorb the shock energy due to rod drop. The function of absorber is performed by fluid labyrinth and disk spring.

The connecting bar is linked with the piston by union swivel. When the reactor need refueling and inspection, the connecting bar is disconnected from union swivel, then the cylinder, piston and control rod support frame are removed from reactor vessel, the connecting bar and control blades remain in the core. 


\subsection{Design parameters}

The main design specifications of NHR-200 are as follows.

$\begin{array}{lc}\text { Design pressure } \mathrm{MPa} & 2.5 \\ \text { Design temperature }{ }^{\circ} \mathrm{C} & 210 \\ \text { Number of control rod } & 32 \\ \text { Step length } \mathrm{mm} & 50\end{array}$

\section{DYNAMIC ANYLISIS}

\subsection{Method}

For the purpose of selecting optimal design parameters, the dynamic behavior of upper hydraulic driven control rod would be investigated sufficiently. The state of control rod must be one of the following four types: holding a stationary position, withdrawal, insertion and scram. The control rod should be tolerated variations of system parameters (flow, temperature etc) and keeps in origin position. With respect to an undue reactivity increase, it is required that only one control rod is withdrawn or inserted one step at a time. During scram the control rod must be moved into the core within the standpoint of safety by opening insertion vale and switching off the pump.

The program for dynamic analysis of the control rod hydraulic driven system is developed based on solving the equations of continuity and momentum using the method of characteristics(1978). The mathematical model includes all component modules (pump, valve, impulse cylinder, drive cylinder, etc.). The flow paths in the drive cylinder and resistance coefficient are taken special care in the model. The program is validated with test data.

\subsection{Steady-state characteristics}

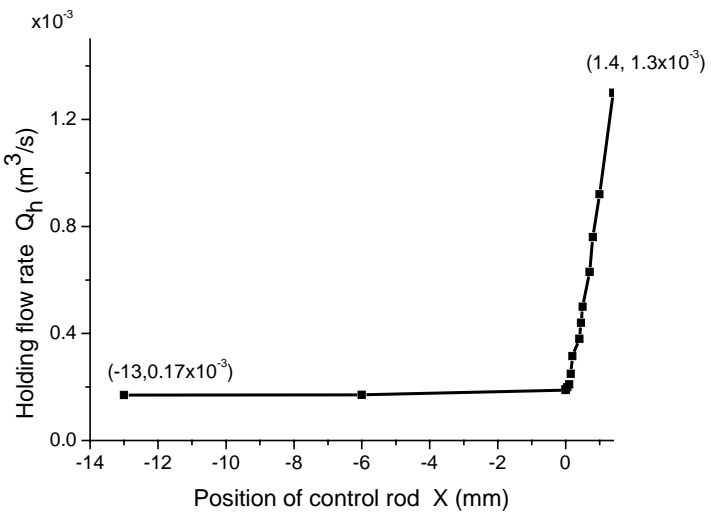

Fig.4 Holding flow rate vs. position of control rod

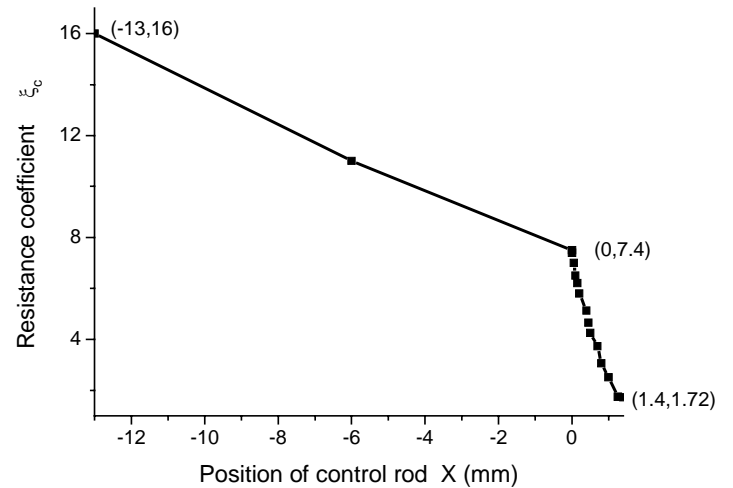

Fig.5 Resistance coefficient vs. position of control rod

The inner diameter of cylinder and feedline pipe is $60 \mathrm{~mm}$ and $25 \mathrm{~mm}$, respectively. The minimum gap between the cylinder and the connecting bar is $0.2 \mathrm{~mm}$. The pump lift is $50 \mathrm{~m}$.

Figure. 4 and Fig.5 illustrate the relationship of hold flow and resistance coefficient at annular gap between the cylinder and the connecting bar to position of control rod respectively. One hold flow is corresponding to definite position of control rod. The resistance coefficient at the gap between the cylinder and the connecting bar is lower while hydraulic drive system is at higher hold flow. The range of hold flow is from $1.36 \times 10^{-3} \mathrm{~m}^{3} / \mathrm{s}$ to $1.7 \times 10^{-4} \mathrm{~m}^{3} / \mathrm{s}$, corresponding resistance coefficient is from 1.72 to 16 .

The reactor will operate at the temperature from $20^{\circ} \mathrm{C}$ to $210^{\circ} \mathrm{C}$. With the increase of the temperature, the density and viscosity of coolant water will decrease. The temperature has influence on the reliability of the hydraulic drive system. Fig.6 and Fig.7 show that the range of hold flow will increase and the hold flow will decrease with the increase of the temperature.

Hold flow is equal to the sum of the flow out from the gap between the piston and cylinder and one out from the gap between the connecting bar and cylinder. The range of hold flow is important factor relating to system stability. With the increase of the diameter of the cylinder, the range of hold flow will decrease. The variation of 
the gap will not change the range of hold flow. If the gap is enlarged, the hold flow curve will translate along the direction of flow rise.

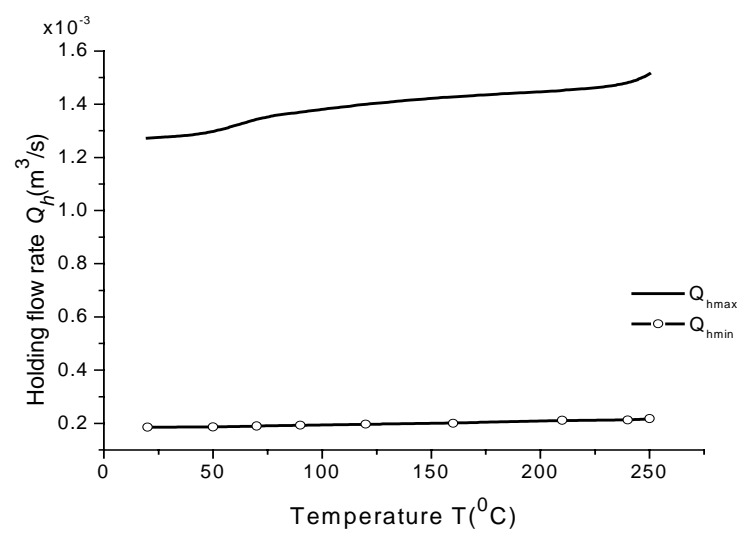

Fig.6 Maximum and minimum hold flow vs. temperature

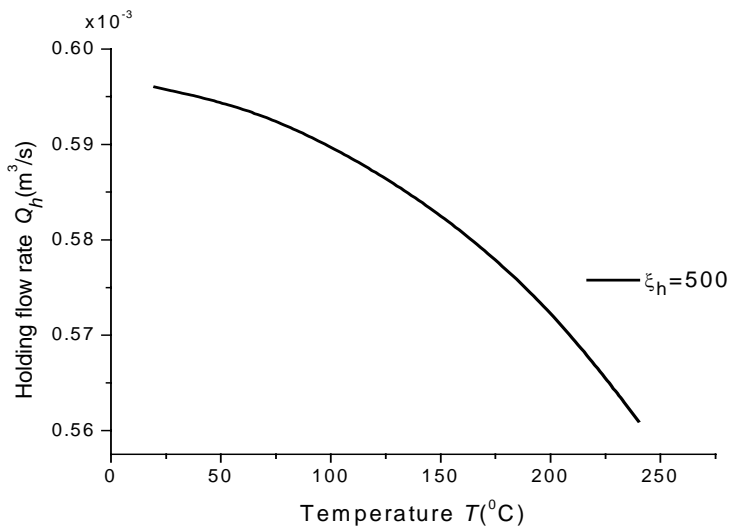

Fig.7 Hold flow vs. temperature

\subsection{Dynamic behavior}
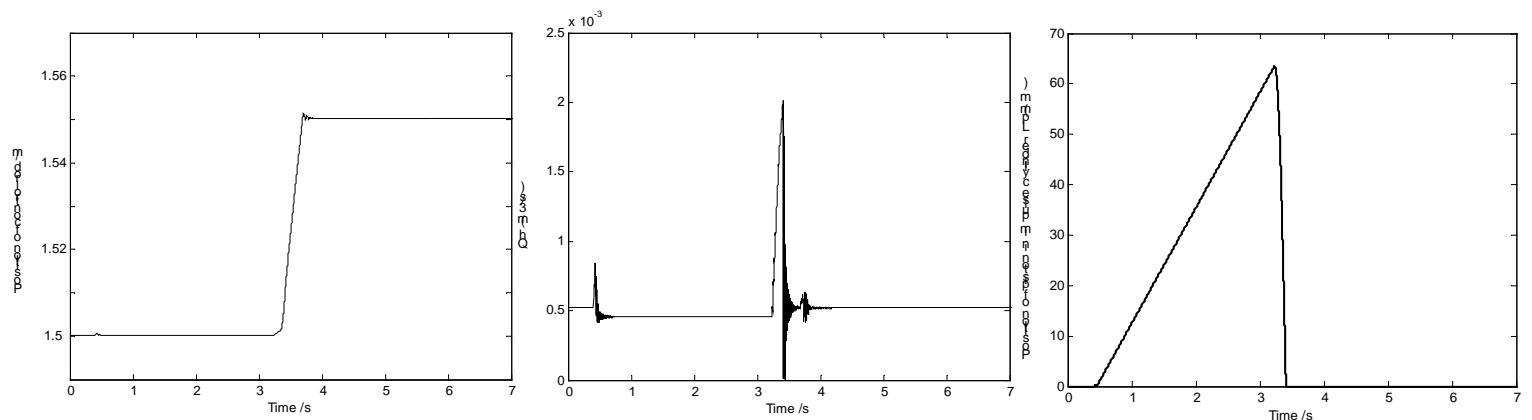

Fig.8 Stepwise withdrawal of control rod

The control rod adjusts the reactor power by three actions, withdraw, insertion and scram. Fig.8 shows stepwise withdrawal of the control rod in $50 \mathrm{~mm}$ step at $20^{\circ} \mathrm{C}$. At the stationary position, the hold flow rate is $0.52 \times 10^{-3} \mathrm{~m}^{3} / \mathrm{s}$, the piston of impulse cylinder is at the bottom. During closing of withdrawal valve, the hold flow rate reduces to $0.45 \times 10^{-3} \mathrm{~m}^{3} / \mathrm{s}$ and the piston of impulse cylinder moves up $63.6 \mathrm{~mm}$. Then withdrawal valve opens, the piston of impulse cylinder is pushed down quickly by high pressure and results in an increase in flow rate $\left(2 \times 10^{-3} \mathrm{~m}^{3} / \mathrm{s}\right)$ causing the control rod move up by $50 \mathrm{~mm}$. At this process the closing time of withdrawal valve is key parameters. Shorter closing time will not generate enough increase in flow rate and control rod will stay origin position after moving up less than $50 \mathrm{~mm}$. Longer closing time will induce too much increase in flow rate and control rod will move up by $100 \mathrm{~mm}$ or more. The acceptable closing time is in a range. The temperature has notable effect on the closing time. With the increase of the temperature, withdrawal valve should be closed longer to move up the control rod by one step.

Stepwise insertion of the control rod is depicted in Fig.9. Bypassing the hold flow by opening the insertion valve temporarily causes a decrease in flow rate and insertion of the control rod by $50 \mathrm{~mm}$. It is similar with stepwise withdrawal. The opening time of insertion valve causing the control rod to move into the core one step 
also is in a range and becomes shorter with decrease of the temperature.

Scram is shown in Fig.10. It is accomplished by simultaneously opening insertion valve and switching off the pump. The control rod begins to drop after a short delay, and attains maximum velocity after about $400 \mathrm{~ms}$, inserts the core entirely within $2.8 \mathrm{~s}$. The increase of temperature results in lower resistance and shorter scram time.

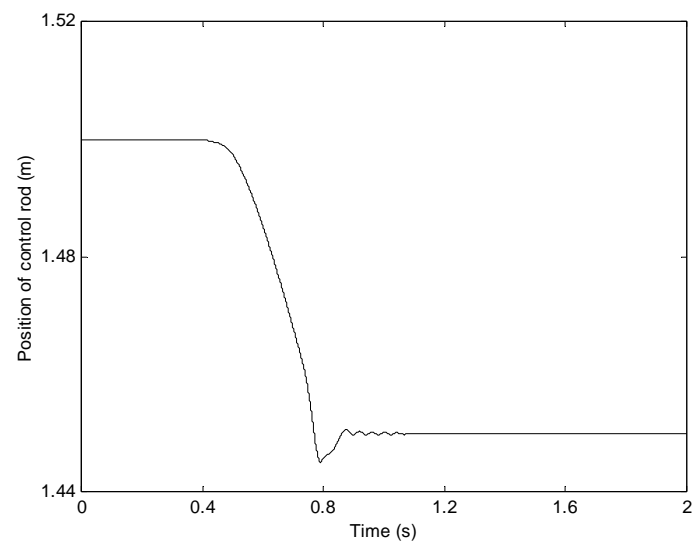

(a) Displacement

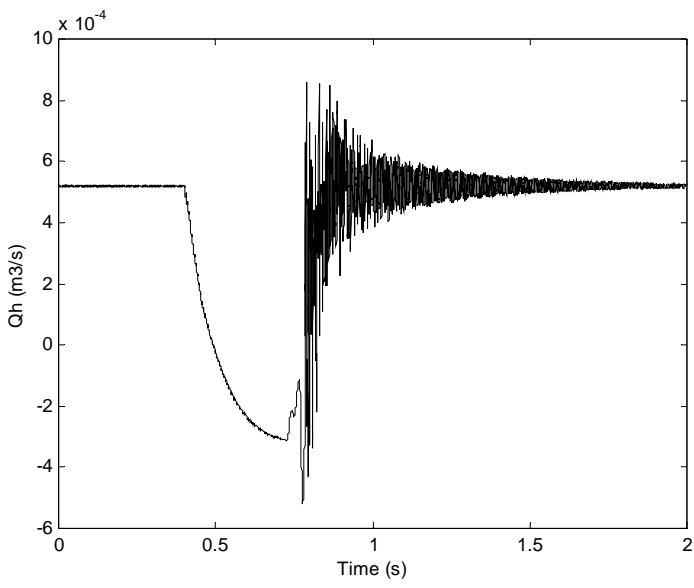

(b) Hold flow

Fig.9 Stepwise insertion of control rod

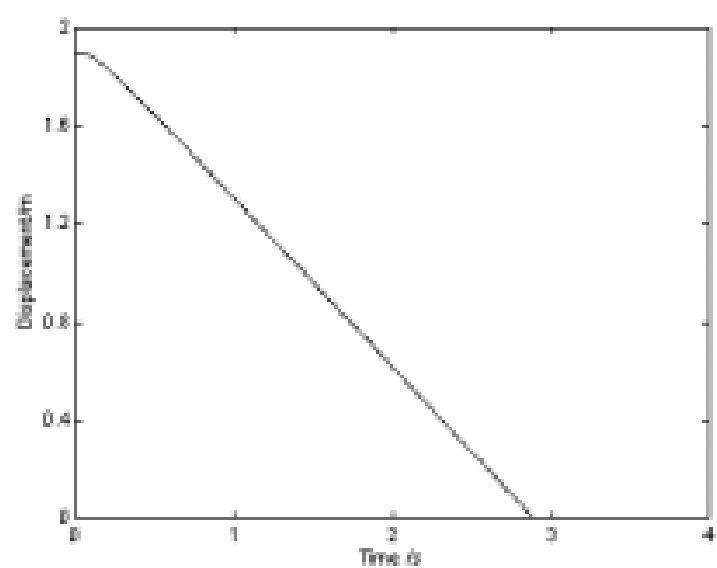

(a) Displacement

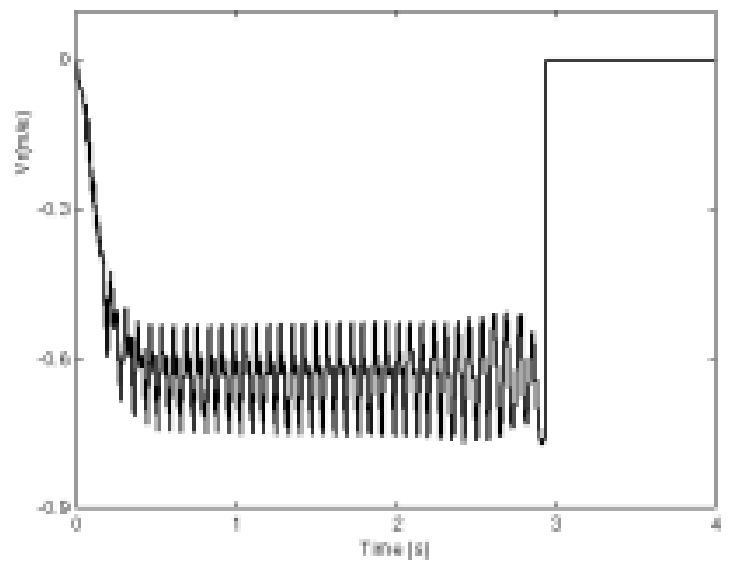

(b) Velocity

Fig.10 scram of control rod

\section{CONCLUSIONS}

The upper hydraulic driven control rod is designed, its characteristics are summarized as follow,

- $\quad$ the drive cylinder is located above the reactor core.

- the number of fuel rods in the active zone is increased.

- neutron absorption is decreased.

- $\quad$ inspection and refueling are simple.

- $\quad$ the results of dynamic analysis show that the upper hydraulic driven control rod will meet the specifications and be used for NHR-200. 


\section{REFERENCES}

Zhang Yajun, Wang Xiuzhen, 2003, Development progress and prospect for industry application of 200MW low temperature nuclear heating reactor, Nuclear Power Engineering,24 (2) : 180 184

Chi Zhongbo, Wu Yuanqiang,Chen Yunxia, 1999, Study and design of hydraulic driving system of control rod, Nuclear Power Engineering (in Chinese) , 20 (1):52 55.

E.B.Wylie, V.L.Streeter, 1978, Fluid transients, Mcgraw-Hill.

Batheja P., Meier W J, Rau P J, 1987,design and testing of the reactor-internal hydraulic control rod drive for the nuclear heating plant, Nuclear Technology,79(11):144 157 